\title{
EL SUJETO MARGINAL EN LA CUENTISTA JULIETA PINTO
}

\author{
The marginal subject in the story teller Julieta Pinto
}

\section{Mayela Vallejos Ramírez*}

\begin{abstract}
RESUMEN
En esta colección de cuentos Los marginados se trabaja una variedad de temas que están relacionados con la vida de las personas en áreas rurales y marginales de la sociedad. La marginalidad social a pesar de que siempre ha existido en el mundo, en esta época contemporánea los estudiosos en la materia le han prestado una mayor atención tal vez por el crecimiento de estos sectores en las sociedades actuales. En general, en estos cuentos se hace un reclamo a la justicia social y los derechos humanos para todos. Los diferentes cuentos que hemos escogido para este trabajo permiten una muestra de los diferentes aspectos de la marginalización. Palabras clave: Julieta Pinto, marginalidad, discriminación, abuso de los derechos humanos, pobreza.
\end{abstract}

\section{ABSTRACT}

The collection of stories, Los marginados develops a variety of topics that are related to the lives of people in rural and marginal areas of society. Although social marginality has always existed in the world, current scholars in the field are given closer attention during our time this is due perhaps to the growth of these sectors in today's societies. A claim to social justice and human rights for everyone is generally expressed in these stories. The different stories we have chosen for this essay are clear examples of the different aspects of marginalization.

Key Words: Julieta Pinto, marginality, discrimination, abuse of human rights, poverty. 
Para Julieta el acto de escribir nunca fue un acto de amor para ella misma, es un acto de amor hacia los demás. Daniel Gallegos

\section{Introducción}

Julieta Pinto (1922) es, sin lugar a dudas, una las mejores cuentistas y novelistas de la segunda mitad del siglo veinte hasta nuestros días. Ha publicado 16 libros entre novelas y cuentos y ha sido galardonada con importantes premios nacionales. En 1969, obtuvo el premio Nacional Aquileo J. Echeverría en novela y en 1970 y 1993 el Premio Nacional Aquileo J. Echeverría en cuento. En 1996, le fue concedido el Premio Nacional de Cultura Magón. Su trabajo siempre se ha enfocado en la denuncia social; tanto en sus cuentos como en sus novelas sobresale su solidaridad para con los campesinos, los niños y las mujeres.

Coincidimos con Luz Ivette Martínez cuando enfatiza que la narrativa de Pinto es una de denuncia social que quiere dejar una concientización en el lector de la realidad de muchos sectores de la sociedad costarricense:

\begin{abstract}
Julieta Pinto sobresale, también en el ámbito social del país, por sus esfuerzos en beneficio de los marginados. Ha sido una mujer que ha vivido constantemente preocupada por los humillados y ofendidos, por todos aquellos que padecen las consecuencias de una sociedad de grandes desigualdades sociales. Sus esfuerzos mayores los ha encaminado a lograr derechos para los niños y campesinos. Esta labor social de Julieta Pinto está estrechamente vinculada a su narrativa. En repetidas ocasiones, ella ha confesado que su obra tiene carácter de denuncia y que va encaminada a conseguir un despertar de conciencia en los costarricenses. (1987: 90)
\end{abstract}

La temática de sus cuentos se desarrolla dentro de un estilo sencillo por la simplicidad del lenguaje, pero a la vez tiene un gran manejo de las técnicas narrativas como son los monólogos interiores, los cambios temporales, las retrospecciones, el contrapunto y el manejo de los diferentes planos narrativos. También, utiliza magistralmente el tratamiento psicológico de sus personajes, lo cual le permite profundizar en el desarrollo de los mismos. Estos son presentados como seres humanos creíbles y no como caricaturas o estereotipos de la sociedad. Sus temas son tratados con gran realismo, lo cual nos permite penetrar en el mundo de los marginados, de los olvidados y de los despreciados desde una perspectiva más humana. A pesar que la temática ahonda en estos temas, no reina la crueldad o la fealdad que sería más propio del naturalismo. Aunque, sí se puede apreciar un determinismo de carácter fatalístico en algunos de sus cuentos producto de la indiferencia de la sociedad que no le interesa el porvenir de los más desfavorecidos de la sociedad. Sin embargo, el gran humanismo que caracteriza la escritura de esta extraordinaria escritora, el relato se pinta con imágenes fuertes pero tiernas a la vez y en algunas ocasiones hasta con gran sentido del humor. En los personajes encontramos seres humanos completos con sus virtudes y defectos, con sus sueños, sus esperanzas y sus desengaños. Son muchos los textos de Pinto que enfatizan este tópico como lo son Cuentos de la tierra (1963) A la vuelta de la esquina (1975) y Abrir los ojos (1982). Concretamente en este trabajo quiero analizar algunos de los cuentos de Los Marginados (1970) (Premio Aquileo Echeverría) en donde encontramos diferentes aspectos de la marginalización tanto socioeconómica como psicológica.

En esta colección se trabaja una variedad de temas que están relacionados con la vida de las personas en áreas rurales y marginales de la sociedad. A pesar de que la marginalidad social siempre ha estado patente, en esta época contemporánea, los estudiosos en esta temática han prestado una mayor atención a esta situación. Esto quizá sea el resultado del crecimiento de sectores marginados en las sociedades actuales. A nivel mundial se ha marcado una mayor preocupación por la pobreza, la exclusión de algunos grupos, y la vulnerabilidad de estas personas en la sociedad. Adames Mayorga, en su artículo "La crisis de las ciencias sociales y los relatos de la pobreza y la marginalidad", considera que en la actualidad el término de marginalidad está profundamente ligado a la 
ecología urbana de los sesenta que reúne ese grupo de personas reunidas en cinturones de pobreza alrededor de las grandes ciudades de los países en desarrollo. En estos asentamientos abundan las viviendas tipo tugurios que carecen de todos los servicios básicos que un ser humano merece. En estos lugares normalmente reina la delincuencia, el alcoholismo, la drogadicción y la prostitución solo para mencionar unos de los tantos problemas sociales característicos de estos ambientes. La marginalidad vivida por estas personas se puede ver desde diferentes ángulos. Encontramos las personas que emigran del campo a la ciudad en busca de una mejor condición de vida y se ven atrapados en ese submundo de los cinturones de pobreza en donde se ven obligados a vivir y acondicionar su vida a las nuevas circunstancias. También, encontramos a personas que salen de las ciudades hacia el campo en busca de una alternativa diferente para su familia, pero por situaciones ajenas a sus deseos se ven obligados a volver al mundo de donde emigraron. Y por último, nos encontramos con las personas que nacen y crecen en localizaciones marginales sufriendo la discriminación no solamente del sector externo, sino por los mismos miembros del grupo social al que pertenecen.

"El origen histórico de las sociedades de América Latina marca desde el comienzo la aparición de un paralelismo dicotómico, consecuencia de la superposición de culturas que se produjo a partir de la dualidad de valores, estructuras sociales y de regímenes políticos y administrativos" (Borges 2006: 2). Esta dicotomía ha marcado una gran brecha social, la cual ha causado que estos miembros de la sociedad sean ignorados y no puedan por ende tener acceso a todas las estructuras de la sociedad por el rechazo que reciben por razones múltiples. "La situación económica es la base de los problemas sociales pero no podemos obviar que existen problemas culturales que agravan los problemas socioculturales que atraviesa nuestra sociedad" (Borges 2006:3). Estos problemas como es esperado causan conflictos y tensiones entre los grupos. Aunque, como es de esperar, los grupos marginales siempre terminan pagando las peores consecuencias. Lo relevante del trabajo de Pinto es que pone en evidencia los prejuicios de una sociedad que margina al pobre, al campesino, a pesar de que el imaginario colectivo costarricense, se empeñe en hacernos creer que todos somos iguales y que en Costa Rica no existen las diferencias de clase o etnicidad, mito incorporado desde finales del siglo XIX en la cultura costarricense. Virginia Caamaño, refiriéndose a este fenómeno, señala que diversos estudiosos en la materia

(...) han demostrado que durante este periodo se construyó el mito de una Costa Rica, cuya esencia ética y cultural eran blancas, muy blancas y sus ciudadanos, habitantes del Valle Central, descendían directamente de "españoles puros". Eran, además, iguales en su pobreza o al menos en su escasez de medios (...) (2004:27).

Sin embargo, la otra realidad social queda claramente estipulada en estas historias en donde la invisibilidad del "otro" aflora. En general, en estos cuentos, se hace un reclamo a la justicia social y los derechos humanos para todos. Los diferentes cuentos que hemos escogido para este trabajo permiten una muestra de los diferentes aspectos de la marginalidad que viven muchas personas.

\section{Análisis de las historias}

\subsection{La expropiación despiadada}

Empezamos este análisis con el cuento "Tierra ajena" el cual trata una tragedia que ha vivido el campesino en Costa Rica en diferentes épocas de la historia del país: ver desaparecer su tierra a manos de capital extranjero, lo cual sigue siendo un tema muy vigente hasta nuestros días. En el cuento "Tierra ajena" nos encontramos con una pareja de campesinos que decide adentrarse en la montaña para labrarse un mejor futuro para ellos y sus hijos: "No quiero que mis hijos sean peones. Haré una finca para ellos" (Pinto 1970: 9). El deseo por una vida mejor es eminente en este hombre, el cual se dedica en alma, vida y corazón a labrar esa nueva tierra que considera 
el futuro y el patrimonio de su familia: "Los ojos le brillaron de contento al saberse en su hogar, su casa propia, su terreno propio. - Te gusta ¿verdad? Y va a ver dentro de unos años que finca más linda vamos a tener" (Pinto 1970:11). Las condiciones ambientales y climatológicas en esa zona eran bastante hostiles, pero esta familia luchó contra todas las adversidades para sacar adelante sus sueños. Con el pasar de los años, la familia fue surgiendo poco a poco y labrándose un mejor destino. El hombre estaba satisfecho de ver crecer sus sembradíos y poder vender los productos en la ciudad. Estaba arreglando los papeles con un abogado del pueblo para poder obtener los títulos de propiedad que lo acreditarían como el dueño de esas tierras. Esto le hacía sentirse más seguro, porque muy en su interior guardaba el temor que algún poderoso viniera a quitarle esas tierras en las cuales había trabajado con tanto ahínco. Hasta que un día sus pesadillas se fueron convirtiendo en realidad cuando empezaron a escuchar los tractores que destrozaban la selva:

\begin{abstract}
Una tarde llegó del pueblo preocupado. - Me dijeron que hay una compañía sembrando banano en esta región. Vi unos terrenos donde trabajaban y me asusté. Unos tractores enormes arrancan los árboles como si fueran hierbas y devoran la selva a toda velocidad. A ese paso ahorita llegan aquí. (Pinto 1970:12)
\end{abstract}

Una compañía extranjera empezó a penetrar en la montaña y en un instante vio desaparecer todas sus ilusiones porque las autoridades se mostraron indiferentes ante las demandas que este hombre presentó para reclamar el derecho a las tierras que había trabajado por tantos años. Los únicos que tenían derecho eran los extranjeros que venían a ocupar esas tierras con sus plantaciones de banano. Y el pobre hombre se ve marginalizado y expropiado de sus tierras:

Sentados en el corredor de la casa lo vieron venir. $\mathrm{Su}$ cuerpo pequeño y grueso se movía con más facilidad de la que se le creía capaz. Las botas altas entraban y salían de la tierra húmeda con prontitud. Traía un cartapacio debajo del brazo y un revólver en la cintura.

-¿Pedro Segura?
Un movimiento afirmativo fue la respuesta.

-Le traigo una orden de desahucio- dijo abriendo el cartapacio

-La compañía compró estas tierras y quiere que desocupe pronto. Se le pagarán todas las mejoras. Un perito vendrá a valorarlas. (Pinto, 1970:13).

En un instante vio desaparecer seis años de trabajo. Solamente le quedó la frustración de la impotencia al no poder hacer absolutamente nada, como el mismo lo afirma: "-Nada se puede hacer. No tengo título todavía y la compañía le compró no sé a quién.” (Pinto 1970:14). Nótese la ironía de la última afirmación "la compañía le compró no sé a quién". Cuando él ocupó esos terrenos con su familia eran tierras baldías en la montaña. No existían dueños de esas propiedades. La tierra era para el que la trabajara y tenían el derecho de inscribirla como propia. Sin embargo, el abogado que buscó, nunca le realizó ningún trámite y terminó perdiendo lo invertido con el abogado corrupto además de su propiedad. El gobierno realizó un convenio con una compañía extranjera cediéndoles esos terrenos, sin importarles los perjuicios que le iban a causar a los campesinos que estaban establecidos en esa región. Esto deja en manifiesto que el gobierno que se supone que es para el pueblo, no le interesa en realidad la condición socioeconómica de ese sector de la sociedad porque normalmente responde a los intereses de un grupo minoritario poderoso. El porvenir de los grupos más vulnerables no es su mayor preocupación. Piensan que con pagar una indemnización a los desalojados están solventando el problema que están causando. Las voces de los campesinos son aplastadas por una burocracia que no le interesa prestar atención a las quejas de los afectados porque ellos no representan un sector importante de la sociedad. Se les llama resentidos sociales o revoltosos para minimizar su impacto en la sociedad cuando quieren hacer valer sus derechos.

A este hombre y su familia no le queda más remedio que abandonar sus tierras e internarse aún más adentro en la montaña con la esperanza de empezar de nuevo y que los 
invasores no lleguen hasta sus nuevos terrenos. Lo notable de este cuento es la vigencia que tiene, puesto que todavía en la actualidad muchas personas en las áreas rurales se ven afectadas por consorcios internacionales o nacionales los cuales cuentan con el apoyo del gobierno sin importarles que esas actividades afecten un sector de la sociedad. Estos impactos han provocado que grupos marginales queden aún más expuestos a una pobreza mayor $\mathrm{y}$, por ende, a sufrir circunstancias negativas como el hambre y la delincuencia.

\subsection{Manipulados por la necesidad}

Siguiendo la misma línea del cuento anterior, nos encontramos con una historia relacionada con las plantaciones de banano. "El empleo" es un cuento que delata las injusticias que sufrían muchos empleados de las bananeras. Nuestro protagonista, Pedro Fuentes, era un excelente trabajador quien se había ganado el respeto de sus empleadores por ser un hombre dedicado a sus quehaceres. No andaba conspirando contra la compañía bananera, al negarse a ser parte del sindicato: "Su fuerza era tanta que alzaba racimos de banano sin esfuerzo alguno. Los capataces lo distinguieron y lo trataron con la consideración debida a un peón cuyo trabajo rinde más" (Pinto 1970:115). De niño había experimentado las consecuencias que su familia había tenido que pagar porque su padre luchaba contra las injusticias a las que eran expuestos los trabajadores de la compañía:

\footnotetext{
Él había experimentado en carne propia la falta de trabajo de su padre. Había sentido el mordisco del hambre roer sus entrañas los días que llegaba agotado de caminar de una finca a otra en demanda de trabajo, había visto los ojos tristes de la madre contemplar las cinco cabezas que esperaban en vano algo con que llenar sus estómagos. (Pinto, 1970, p.114).
}

Así que Pedro se había dedicado a su trabajo y a darles a su esposa e hijos una buena condición de vida. No quería que su familia pasara las necesidades que él y sus hermanos habían tenido que padecer por culpa de su padre. El reconocía que por su padre sentía un sentimiento encontrado puesto que por una parte admiraba el valor que este hombre tuvo al enfrentarse a la compañía bananera para defender a todos los trabajadores de la explotación, pero por otra parte le resentía que esa situación los hubiera llevado a vivir una vida tan precaria. Al desaparecer el padre, su madre tuvo que hacerse cargo de la familia lavando ajeno, trabajo que le robó la vida de tanto sacrificio. Por esta razón, él prefirió mantenerse alejado de las reuniones de los sindicatos:

Vivía en una de las mejores casas de todas y todas
las tardes al terminar su labor se refugiaba en
ella, para no oír las quejas de los compañeros ni
asistir a esas reuniones clandestinas que le podrían
traer molestias. Con Micaela a su lado hilvanaba
sueños de un futuro seguro con un salario que, al
aumentar gradualmente le permitiera poner a los
hijos a la escuela. -Serán inteligentes y alguno de
ellos llegará a la universidad- le decía a su mujer
que lo escuchaba con atención- y quien sabe hasta
abogado podrá ser. (Pinto, 1970, p.116)

Este hombre estaba claro del futuro que anhelaba para él y su familia. Sin embargo, un día todo cambió cuando uno de sus sobrinos lo vino a buscar para que fuera a ver a uno de sus hermanos que estaba extremadamente enfermo. Al llegar a la casa de Toño, se llevó una fuerte impresión ya que su hermano se encontraba en una condición deplorable. Parecía un anciano y no había nadie quien le pudiera ayudar para llegar al hospital. Al preguntarle a su hermano que le había ocurrido, éste contesto:

-Lo de siempre. Me empujaron a trabajar en las
zanjas y todos los días llegaba el capataz. Mire
Toño no sea tonto, aquí tengo un contrato para un
trabajo mejor si renuncia al sindicato. No tiene nada
más que firmarlo. Y me enseñaba el papel amarillo
que tenía en la bolsa del pantalón. Y uno con el
recuerdo del viejo en la nuca no se atrevía a decir
que sí y los pies reventándose en ampollas que se
enconaban después. (Pinto, 1970:116)

Esta escena familiar, al ver a su hermano y su familia en las condiciones precarias en las que encontraban, trajo todos los recuerdos del pasado vivido y despertó en él un odio que tenía guardado en su alma. En ese instante, 
olvidó todos sus sueños personales y explotó de rabia: "Una cólera honda empezó a formarse en su interior y estalló con violencia con palabras injuriosas: -¡Desgraciados! ¡Hijos de puta! Tendrán que pagarlo algún día" (Pinto 1970:117). El dejó a su hermano con algo de dinero y con la promesa que hablaría con los jefes. Sin embargo, las gestiones que hizo fueron en vano. Nadie le resolvió el problema de su hermano. La frustración se fue apoderando de él y empezó a asistir a las reuniones a pesar que los capataces le aconsejaban que no se involucrara en esas cosas porque iba a perder todo lo que había ganado durante esos años, él era un buen elemento para la compañía y que pronto lo harían capataz:

-No sea tonto. Esas cosas suceden desde que el mundo es mundo y nadie las va a cambiar. Si quiere un consejo renuncie a ser dirigente y yo le prometo que el próximo año lo nombramos capataz. Eso sí, quítese esas debilidades que no sirven para el mando. La única cosa que se debe tener en cuenta es el mayor provecho para la compañía. (Pinto 1970:117).

Pedro no tiene el corazón insensible que tienen los jefes de la compañía a los cuales no les interesa para nada la vida de los trabajadores. Están interesados solamente en los beneficios económicos de la compañía. Cualquier elemento que se interponga tiene que ser eliminado o castigado por la insurrección. A pesar de que Pedro estaba consciente del peligro en que ponía la estabilidad económica de su familia, decide convertirse en un líder sindical con el sueño de poder lograr algunas mejoras para los compañeros de trabajo. Desde ese momento, su futuro dio un giro de 180 grados, su vida cambió completa y tuvieron que dejar atrás la vida cómoda que hasta ese momento habían disfrutado. Pedro sentía que la decisión que había tomado era la mejor para todos. Sin embargo, todo empezó a desmejorar. No podía encontrar trabajo por ninguna parte a pesar de su gran fama de buen trabajador. El peso negativo que le daba su afiliación sindical importunaba mucho más. La desesperación empezó a apoderarse de este hombre al no poder encontrar trabajo. Hasta que un día, le dieron trabajo en una de las fincas. Le dieron un trabajo de los más difíciles y le advirtieron que si quería conservarlo tenía que olvidarse de los asuntos sindicales. El hombre “apretó los puños y la boca con fuerza y caminó lentamente a la barraca" (Pinto 1970:119). Sabía que no tenía otra opción si quería conservar el trabajo. Tenía una familia que mantener.

En este cuento vemos como la persona se ve vencida por la compañía bananera que no tiene ninguna misericordia por sus empleados. La explotación y el trato injusto de los trabajadores eran evidentes. La mano enérgica de la compañía era mucho más poderosa que las perseverancias de las personas que luchaban por un trato más humano. Al final, no tienen más remedio que bajar la cabeza y aceptar los tratos injustos de la compañía para poder mantener a su familia.

\subsection{Crueldad y desamparo}

En "El regalo" nos encontramos ante la crueldad de los seres humanos hacia aquellos seres menos agraciados. Aquí la marginación toma otra característica puesto que ésta se ve como un fenómeno en donde el mismo grupo social no permite el mejoramiento de la calidad de vida de uno de sus miembros por ser menospreciado por sus características físicas. La historia se inicia cuando la madre de unos niños muere y todos estos son tomados en adopción por los vecinos, excepto la mayor que es abandonada a su suerte por ser una niña bastante fea. La única persona que se la lleva a vivir a su casa es una mujer dueña de una venta de comida: "-Venite conmigo Hilda, para dejar almuerzos no se necesita ser bonita" (Pinto 1970:39). Esta pobre niña crece en un gran desamparo bajo la crueldad de doña Matilde que no tiene para ella nunca una muestra de cariño. Lo único que le interesa es que Hilda trabaje de sol a sol. Relativamente es explotada y maltratada por doña Matilde:

La buena señora tenía fama de impaciente y ella lo pudo comprobar en los coscorrones y en los pellizcos que amorataban sus bracillos enclenques. ¿Que los almuerzos! ¡Que la leña! ¡Que soplar el fuego hasta que sus ojos se derretían! ¡Que te levantés más temprano, haragana! ¡Que solo para comer servís! Sus pies corriendo de un lado para otro, incansable. (Pinto 1970: 39-40). 
La voz narrativa denuncia uno de los problemas más comunes de las sociedades capitalistas que es la explotación de menores en el campo laboral. Aquí se puede apreciar que a esta niña se le priva de la posibilidad de asistir a la escuela como los demás niños. No existe ninguna persona que levante la voz para defenderla. Ven el trabajo que tiene que hacer para doña Matilde como algo normal. Como podemos apreciar, la pobreza también incide en la infancia. Nunca se ha visto un niño rico trabajar. La relación entre pobreza familiar y trabajo infantil es muy evidente. En el caso de Hilda, ella representa mano de obra barata, sumisa y vulnerable. Esto nos lleva a pensar que una niña como ella será una futura adulta analfabeta de por vida, nunca tendrá un título elemental. Por lo cual, no podrá defender sus derechos, tampoco cuando sea adulto.

En esencia, a lo largo de toda su vida sufre el rechazo de sus hermanos, de los adultos y hasta de los niños que se burlan de ella:

\begin{abstract}
No hubo tiempo para ir a la escuela y las burlas de los chiquillos la acompañaban siempre que salía de casa. "Te apuesto que la mamá de Hilda vio muchos sapos cuando iba a nacer." "Yo creo que fue más bien al mono de la pulpería”. (Pinto, 1970, p 40).
\end{abstract}

La pobre niña aparentaba indiferencia ante las burlas de los otros niños, pero muy en su interior deseaba tener la oportunidad de jugar con ellos y compartir la alegría de saberse una niña como todos. Desafortunadamente, todo el mundo a su alrededor la trata como si ella fuera desechable. Hilda se va convirtiendo en un objeto y va perdiendo su propia humanidad e identidad. Recordemos que es en la niñez en donde se forjan los valores, las creencias y el entendimiento del entorno. Hilda crece como un animalito salvaje que lo único que recibe de los demás es el desprecio, la burla, el maltrato físico y emocional. No sabe lo que es tener una familia y menos aún sentirse amada y respetada. Esto provoca que sea una niña solitaria, nerviosa, arisca, y asustadiza.

Con el pasar de los años, Hilda se va convirtiendo en una jovencita muy sensual: “Cumplió quince años y la naturaleza la dotó de todos los dones que da a la mujer para atrapar al hombre. Sus formas se distinguían a través de la ropa y más de una vez sorprendió una mirada de deseo" (Pinto 1970:42). Fue así como un día el encargado del cafetal empezó a desear el cuerpo de esta inocente criatura. Hilda no pudo percibir nada malo en las intenciones del hombre porque estaba ávida de cariño. Por el contrario, las atenciones del capataz la llenaron de felicidad. Por primera vez, encontró a alguien que la tratara diferente y eso fue llenando la soledad que la acompañaba. No pudo reconocer que lo único que le interesaba a este hombre era poseerla físicamente puesto que estaba casado y con cinco niños. Después de un tiempo, Hilda quedó embarazada y el hombre al notar el embarazo, la abandona dejándola en un desamparo mayor. Doña Matilde la obliga a abandonar su casa y la pobre Hilda se ve obligada a buscar otra manera de subsistir para mantener a su hijo. Otros hombres llegan a su vida pero todos con la misma intención. Esto se le convierte en un ciclo enfermizo porque lo único que logra es llenarse de hijos. En esta parte de la historia, nos encontramos con un personaje casi al borde de la destrucción. Ella no tiene ni voz ni voto en las acciones que pasan en su vida. El uso de su cuerpo es la única alternativa que tiene para poder sobrevivir y mantener a sus hijos. Al contraer una enfermedad venérea, tiene que pasar largo tiempo en el hospital. Cuando regresa a su casucha todos sus hijos están viviendo con otras familias y ninguno de ellos, excepto el más pequeño, quiere regresar con ella. Este es un evento muy devastador para la joven que ahora experimenta el desprecio y rechazo de sus propios hijos.

Es este momento de su vida es que conoce a una mujer muy generosa que la trata con cariño genuino por primera vez. Se crea una linda amistad con esta mujer que muestra gran solidaridad para con ella. Este sentimiento, Hilda nunca lo había experimentado en su vida:

Sus ojos acostumbrados a mirar desprecio o indiferencia encontraron de pronto una mirada compasiva y se sorprendió ante ella. Hilda supo que existía alguien que se preocupaba por su bienestar. 
Que cada sábado le daba alimentos y le conseguía ropa y hasta una cobija. (Pinto 1970:43).

Hilda no sabía cómo compensar a su amiga por tanta generosidad. Así que un día decidió alistar lo mejor que pudo a Gerardito para darle como regalo a su amiga, su único tesoro. Pero para su sorpresa, la amiga no le aceptó al niño. Ella regresa feliz a su casa con su hijito tratando de entender la generosidad de esta mujer.

Este cuento está cargado de gran esperanza y positivismo porque a pesar de que Hilda siempre fue despreciada por todos, encuentra en su último hijo y su nueva amiga toda la ternura que siempre había deseado tener. Nos deja el sentimiento que a partir de este instante la vida de esta mujer va a mejorar. Se resalta, el sentimiento de solidaridad que todavía se puede esperar de algunos seres humanos en la sociedad.

\subsection{La superstición como trasfondo cultural}

Otro aspecto que presenta esta colección es la ingenuidad o la superstición que rodea la vida de muchas de las personas pertenecientes a estratos bajos de la sociedad. La superstición suele basarse en tradiciones populares que se transmiten de generación en generación. Esto quiere decir que dentro de una comunidad, los ancestros trasmiten algunas creencias que pueden favorecer la buena o la mala suerte. Muchas de estas supersticiones forman parte de nuestro acervo cultural o tradicional. Por esa razón, tienen un gran peso emocional en las personas. A veces esta actitud supersticiosa, no les permite a las personas avanzar en la vida porque se ven atrapados en esos pensamientos negativos. La religión puede ser un canal muy efectivo para incrementar la superstición en ciertos grupos de la sociedad, especialmente cuando la ignorancia puede ayudar a confundir ciertos dogmas o creencias religiosas con ideas supersticiosas. En la actualidad, mucha gente combina creencias religiosas con supersticiones. Esto hace que un hombre católico pueda preferir no pasar por debajo de una escalera ya que, más allá de su fe cristiana, considera que dicha acción traerá la desgracia.

Un cuento sumamente humano y conmovedor es el titulado "Desobediencia" en donde una pareja tiene relaciones íntimas en un Viernes Santo a pesar de las suplicas de la mujer que estaba consciente de la trasgresión que estaban cometiendo: "El padre había dicho en el púlpito que en la Semana Santa se debían interrumpir las relaciones entre marido y mujer, sobre todo el Viernes Santo, pues podía nacer un monstruo" (Pinto 1970: 20). La mujer queda embarazada y a pesar de todas las cosas que hizo para provocarse un aborto espontáneo, no pudo lograrlo. Los siguientes meses fueron la más grande pesadilla para esta pareja que estaba convencida que el hijo que esperaban, era producto del pecado y que la criatura sería un ser monstruoso, hijo del diablo. Todo el embarazo fue un verdadero calvario porque la pobre mujer tenía un estómago descomunal que la invalidó en una cama. La esposa le había pedido a su marido que al nacer la criatura la matara para acabar con la desgracia que él mismo había provocado por no guardar las reglas de la iglesia. Sin embargo, al nacer las criaturas, ya que resultaron ser gemelas, pudo más el instinto maternal y termina la mujer arrullando a sus dos bebés con una gran cariño: "Paula abrió los ojos y sus brazos se extendieron para recibir dos niños blancos y gordos que acurrucó con ternura en su seno" (Pinto 1970: 23). Aquí se puede ver la gran humanidad de la escritora que nos deja establecido que el amor tiene mucho más poder que las creencias o supersticiones a las que muchas personas se ven impuestas.

\subsection{Bajas pasiones y remordimiento}

Con gran maestría e humanidad, percibimos el tratamiento que le da a temas tan delicados como el incesto y abuso sexual. En el relato "El amigo", un hombre tiene relaciones íntimas con su hijastra. Un día este hombre visita a uno de sus amigos para que lo ayude con el cargo de conciencia que lo atormenta noche y día después de lo acontecido. Nos damos cuenta 
que este hombre no es un ser desalmado. Es simplemente un ser humano que se ha dejado llevar por sus pasiones desenfrenadas sin medir las consecuencias. La joven, aparentemente es una niña con algún tipo de retardo mental. Este hombre siempre llegaba temprano a casa y fue dejando que la ternura que la joven le profesaba, lo confundiera con una provocación o insinuación de parte de ella: "Se acerca a mí siempre con la misma sonrisa y al coger el plato sus manos tibias se posan en las mías. Uno es hombre, qué demonio, y esas manos y esa sonrisa me hicieron estamparle un beso un día" (Pinto 1970: 127). Lo interesante de este relato es que la narradora nos deja apreciar esta situación desde una óptica muy objetiva. La acción que comete este hombre es una cobardía, una vileza, pero la narradora no lo enjuicia. Simplemente, nos plantea lo acontecido y nos deja a nosotros como lectores en libertad para realizar nuestro propio veredicto. Este hombre equívocamente se deja llevar por el instinto, por la pasión. No mide las consecuencias. No se da cuenta que lo que está haciendo es un crimen, no sólo porque es su hijastra sino también porque es una niña con problemas mentales. Al quedar embarazada la niña, todo queda al descubierto. $\mathrm{Y}$ el hombre no solo queda expuesto ante su esposa, sino ante la sociedad que lo rechaza y lo señala como un desalmado. Las palabras de la mujer, le hacen caer en cuenta de su terrible acto: "Comencé a sentir un remordimiento que me ha ido creciendo cada día, no me deja trabajar y se empeora cuando tomo unos tragos en la pulpería para ver si acaso olvido" (Pinto 1970:128). Él es consciente que lo que hizo no tiene perdón. Por eso, le dice a su amigo "Son cosas del demonio, solo así puede ser uno tan cochino, tan sin alma" (Pinto 1970:127). Lo que lo lleva a tomar una decisión muy drástica con relación a su vida al no poder más con el remordimiento. Por esta razón, va en busca de un amigo para que le preste 30 colones para alquilar un revolver y acabar con su vida. A lo cual el amigo responde: "-Y después, ¿Quién me paga los treinta pesos?" (Pinto 1970:129). Es interesante, como sorpresivamente, la narradora baja el tono al final de la historia para darnos un desenlace totalmente inesperado cargado de ironía. A pesar de la seriedad del tema, no podemos evitar una sonrisa por el realismo tan crudo que muestra el amigo que está más preocupado por su dinero que por la situación emocional por la que está pasando su amigo. Como se puede observar en esta historia, un tema tan fuerte como es el incesto la escritora nos lo presenta como una fatalidad que suele ocurrir probablemente con mucha más frecuencia en los sectores marginales de la sociedad por la falta de educación, por la ignorancia y por las condiciones de vida que llevan la mayoría de estas personas.

\subsection{La esperanza en la adversidad}

El último cuento que examinaremos de esta colección se llama "El maestro rural". En esta historia nos encontramos con un joven aspirante a maestro, el cual ha sido asignado a una escuela rural por falta de encontrar educadores que quieran enseñar en esa zona del país. El emprende su viaje con gran entusiasmo de poder impartir sus conocimientos con los niños de ese pueblo perdido en la montaña. Cuando lo deja el autobús, un hombre pobre y flaco semejante a los caballos, lo está esperando para ayudarlo a concluir el viaje. Al llegar al pueblo, triste y desolado se lleva la mayor desilusión de su vida. La cual se incrementa con la noticia que no existe ni siquiera una escuela donde impartir las clases. Los lugareños lo están esperando para que él con sus conocimientos los dirija a construir la escuela: "¿Cómo decirles que él no tenía la menor idea de cómo se construía una escuela? ¿Cómo explicarles que el Ministerio debió de haber mandado un ingeniero antes que a él" (Pinto 1970:106). A pesar del miedo que sentía, se puso manos a la obra con los varios hombres que estaban dispuestos a seguir sus instrucciones y en quince días pudieron construir la escuela. Las condiciones no eran las más óptimas pero el entusiasmo de los niños y de los adultos fue ilusionando al joven aprendiz de maestro que muy en sus adentros soñaba con volver a la ciudad, concluir sus estudios y vivir 
una vida mucho más cómoda que la que ahora tenía en ese pueblo alejado de la civilización. Las inclemencias del tiempo hicieron que su estancia fuera mucho más difícil:

Los aguaceros copiosos trajeron nuevas dificultades: los ríos se crecieron y casi arrasan el pueblo. La escuela tenía más de un metro de agua y por tres días seguidos, bajo torrentes de lluvia, tuvo que trabajar al lado de los hombres tratando a ahondar el cauce del río. (Pinto 1970:107).

Poco a poco se va integrando a la comunidad, realizando más labores de las de un simple maestro. Empieza a apreciar la sencillez de las personas y el tesón con que se labraba el futuro. Hasta llegó a fungir como enfermero, consejero y psicólogo del pueblo:

Él, que le había tenido horror a la sangre, tuvo que vendar un brazo casi colgando de un machetazo, curar infecciones repletas de pus que le impedían comer de día, y ser el intermediario en las dificultades matrimoniales: "Porque la Lola se quiere meter en mi matrimonio y robarme al marido. Como es sola, anda como perra en celo queriendo agarrar cualquier hombre". "Pero si Paco fue novio mío antes de casarse con Mercedes. Ella fue la que me lo quitó" La voz de él aconsejando. "Pero se casaron, Lola, y tienen cuatro hijos". "Bueno, con eso sí me convence, pero vea que es sólo por los chiquillos". (Pinto 1970:108).

Sin embargo, llegó el tiempo de regresar a la civilización. Su primer impulso fue alejarse de ese sitio y reintegrase a la vida que había dejado en la ciudad. Sin embargo, a medida que se alejaba del pueblo recordaba la carita de los niños, de los adultos que veían irse con él la esperanza de un mundo mejor. Empezó a meditar si el próximo maestro que llegara los aprendería a querer tanto como él. En un acto de solidaridad y amor por las personas de ese pueblo decide regresarse con ellos para seguir la labor que había empezado. Este hombre antepone sus deseos personales por los de todo un pueblo. La convivencia con los lugareños le creó una concientización mayor que no se aprende en los salones de la universidad. Aprendió que él podía hacer un verdadero cambio en las vidas de estas personas.

\section{Consideraciones finales}

En este trabajo, se han analizado seis cuentos de los dieciocho que componen esta colección. Los escogimos porque ellos nos dan una visión general de la complejidad temática que conforma este libro de cuentos. La voz narrativa denuncia aspectos diversos de los sectores más pobres de la sociedad. Estas sociedades se caracterizan por la incapacidad de resolver sus problemas por la falta de interés que muestran los gobiernos indiferentes a sus necesidades. La marginalidad afecta varios aspectos de la vida de las personas. Normalmente, cuando se piensa en los sectores marginales de la sociedad, especulamos mayormente en el factor económico, pero muy poco en el aspecto humano. Como hemos podido apreciar en estos cuentos, la pobreza conlleva a una miseria social y emocional. Es la causante de muchos otros problemas que los sectores más privilegiados puntualizan como una lacra social. Dentro de estos fenómenos sociales se enfatizan las debilidades humanas como el incesto que es tan delicadamente expuesto en uno de estos cuentos o la prostitución impuesta como único medio para sobrevivir.

Lo más impactante de este libro publicado en 1970, es como conserva una gran vigencia hasta nuestros días porque el desarrollo desigual, el desequilibrio social y la marginalización de muchos sectores de la sociedad siguen siendo una realidad actual. La globalización que vivimos en la actualidad incrementa esa disparidad social y económica. Los grandes consorcios no toman en cuenta el prejuicio que sus industrias multinacionales causan a los sectores más vulnerables de la sociedad. Por el contrario, da la impresión que se nutren de la mano de obra barata y de las necesidades en que viven estas personas. Basta una mirada rápida al mundo que nos presenta Pinto para ratificar que los problemas expuestos en estas historias siguen manteniendo validez.

Julieta Pinto nos prueba que todos los seres humanos tenemos los mismos sueños $\mathrm{y}$ aspiraciones, las mismas preocupaciones o tragedias. Los marginados en pocas palabras 
es un libro lleno de una gran sensibilidad y humanidad que nos permite como lectores sensibilizarnos con sectores marginales de la población que muchas veces por ignorancia o por desidia no queremos reconocer como parte de nuestra problemática social actual.

\section{Bibliografía}

Adames Mayorga, Enoch. 2004. "La crisis de las ciencias sociales y los retos de la pobreza y la marginalidad". En: Revista Tareas 117: 5-14.

Borges Machín, Anaiky Yanelí. 2006 “La marginalidad: su relación con fenómenos sociales afines e importancia para el trabajo en las comunidades". Monografias. www.monografias.com/trabajo68.

Caamaño, Virginia. 2004. “Cocorí: Una lectura desde la perspectiva de la construcción identitariacostarricense". En: Revista Káñina, XXVIII (Especial): 27-32.

Martinez S, Luz Ivette. 1987. Carmen Naranjo y la narrativa femenina en Costa Rica. San José: Editorial Universitaria Centroamericana.

Pinto, Julieta. 1970. Los marginados. San José: Editorial Costa Rica.

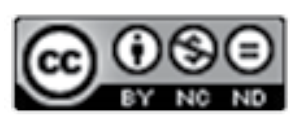

Este obra está bajo una licencia de Creative Commons

Reconocimiento-NoComercial-SinObraDerivada 4.0 Internacional. 